\title{
Correction to: Within-Individual Age-Related Trends, Cycles, and Event-Driven Changes in Job Performance: a Career-Span Perspective
}

\author{
Guido Alessandri ${ }^{1}$ (D) Donald M. Truxillo ${ }^{2} \cdot$ John Tisak $^{3} \cdot$ Corrado Fagnani $^{4} \cdot$ Laura Borgogni $^{1}$ \\ Published online: 9 December 2019 \\ (C) Springer Science+Business Media, LLC, part of Springer Nature 2019
}

\section{Correction to: J Bus Psychol}

https://doi.org/10.1007/s10869-019-09645-8

There were mistakes both in one's of authors' names and in the affiliation.

"Laura Borgogni Sapienza" should be "Laura Borgogni". Moreover, affiliation 5 should be deleted and Laura Borgogni should be affiliated to Affiliation 1 (Department of Psychology, Sapienza University of Rome, Via dei Marsi 78, 00185 Rome, Italy).

The original article has been corrected.

Publisher's Note Springer Nature remains neutral with regard to jurisdictional claims in published maps and institutional affiliations.

The online version of the original article can be found at https://oi.org/ 10.1007/s10741-019-09828-8

\footnotetext{
Guido Alessandri

guido.alessandri@uniroma1.it

1 Department of Psychology, Sapienza University of Rome, Via dei Marsi 78, 00185 Rome, Italy

2 Portland State University, Portland, OR 97201, USA

3 Bowling Green State University, Bowling Green, OH 43403, USA

4 National Institute of Health, Rome, Italy
} 